\title{
Reconstructing the directionality of coupling between cortical populations with negative phase lag
}

\author{
Fernanda S Matias ${ }^{1 *}$, Leonardo L Gollo ${ }^{2}$, Pedro V Carelli ${ }^{3}$, Mauro Copelli ${ }^{3}$, Claudio R Mirasso ${ }^{4}$ \\ From 24th Annual Computational Neuroscience Meeting: CNS*2015 \\ Prague, Czech Republic. 18-23 July 2015
}

Understanding how information is processed in the brain is one of the key areas in neuroscience research. Different tools have been employed to reconstruct directional influence and to infer the effective connectivity between distinct brain regions. Particularly, it has been shown [1] that in non-linear delay-coupled oscillating systems exhibiting a negative phase lag, Granger causality (GC) might not provide the correct direction of information flow (from the driver to the receiver). Such systems have been studied before in the theoretical framework of Anticipated Synchronization (AS) developed in the field of dynamical systems [2]. This counterintuitive synchronization regime can be a stable solution of two dynamical systems coupled in a master-slave (driverreceiver) configuration when the slave receives a negative delayed self-feedback. Recently, it has been shown that unidirectional coupled neuronal population models can also exhibit AS [3]. In these cortical like populations the delayed feedback has been replaced by a dynamical inhibitory loop mediated by interneurons. Here we show that in these biologically plausible models, GC provides the correct directionality of the coupling for both positive and negative phase differences. In fact, when compared to experimental data in the primate cortex our model reproduces experimental phase lags, coherence spectra and GC spectra [3].

\section{Authors' details}

'Instituto de Física, Universidade Federal de Alagoas, Maceió, AL 57072-900, Brazil. ${ }^{2}$ Systems Neuroscience Group, Queensland Institute of Medical Research, Brisbane QLD 4006, Australia. ${ }^{3}$ Departamento de Física,

\footnotetext{
* Correspondence: fernanda@fis.ufal.br

${ }^{1}$ Instituto de Física, Universidade Federal de Alagoas, Maceió, AL 57072-900, Brazil

Full list of author information is available at the end of the article
}

Universidade Federal de Pernambuco, Recife PE 50670-901, Brazil. ${ }^{4}$ Instituto de Fisica Interdisciplinar y Sistemas Complejos, CSIC-UIB, Campus Universitat de les Illes Balears, E-07122 Palma de Mallorca, Spain.

Published: 18 December 2015

\section{References}

1. Vakorin VA, Krakovska O, Mclntosh AR: On Complexity and Phase Effects in Reconstructing the Directionality of Coupling in Non-linear Systems. Directed Information Measures in Neuroscience Springer Berlin Heidelberg; 2014, 137-158.

2. Voss HU: Anticipating chaotic synchronization. Phys Rev E 2000, 61:5115-5119.

3. Matias FS, Gollo LL, Carelli PV, Bressler SL, Copelli M, Mirasso CR: Modeling positive Granger causality and negative phase lag between cortical areas. Neurolmage 2014, 99:411-418.

doi:10.1186/1471-2202-16-S1-P166

Cite this article as: Matias et al:: Reconstructing the directionality of coupling between cortical populations with negative phase lag. BMC Neuroscience 2015 16(Suppl 1):P166.
Submit your next manuscript to BioMed Central and take full advantage of:

- Convenient online submission

- Thorough peer review

- No space constraints or color figure charges

- Immediate publication on acceptance

- Inclusion in PubMed, CAS, Scopus and Google Scholar

- Research which is freely available for redistribution

Submit your manuscript at www.biomedcentral.com/submit
() Biomed Central 